\title{
Integrated community-directed intervention for schistosomiasis and soil transmitted helminths in western Kenya - a pilot study
}

\author{
Pauline NM Mwinzi ${ }^{*}$, Susan P Montgomery ${ }^{3}$, Chrispin O Owaga ${ }^{1}$, Mariam Mwanje², Erick M Muok${ }^{1}$, John G Ayisi ${ }^{1}$,
} Kayla F Laserson ${ }^{4}$, Erick M Muchiri ${ }^{2}$, W Evan Secor ${ }^{3}$ and Diana MS Karanja ${ }^{1}$

\begin{abstract}
Background: Schistosome and soil-transmitted helminth (STH) infections are recognized as major global public health problems, causing severe and subtle morbidity, including significant educational and nutritional effects in children. Although effective and safe drugs are available, ensuring access to these drugs by all those at risk of schistosomiasis and STHs is still a challenge. Community-directed intervention (CDI) has been used successfully for mass distribution of drugs for other diseases such as onchocerciasis and lymphatic filariasis. A national control programme is yet to be instituted in Kenya and evidence for cost-effective strategies for reaching most affected communities is needed. This study evaluated the effectiveness and feasibility of the CDI strategy in the control of schistosomiasis and STHs, in East Uyoma location, Rarieda district, a community of western Kenya that is highly endemic for both infections.
\end{abstract}

Results: Pre-treatment prevalence of S. mansoni averaged 17.4\% (range 5-43\%) in the entire location. Treatment coverage in different villages ranged from 54.19 to $96.6 \%$ by community drug distributor (CDD) records. Assessment from a household survey showed coverage of $52.3-91.9 \%$ while the proportion of homesteads (home compounds) covered ranged from 54.9-98.5\%. Six months after one round of drug distribution, the prevalence levels of S. mansoni, hookworm and Trichuris trichura infections were reduced by $33.2 \%, 69.4 \%$ and $42.6 \%$ respectively.

Conclusions: This study shows that CDI is an accepted and effective strategy in the mass treatment of schistosomiasis and STH infections in resource constrained communities in Kenya and may be useful in similar communities elsewhere. A controlled trial comparing CDI and school based mass drug administration to demonstarte their relative advantages is ongoing.

\section{Background}

Schistosome and soil-transmitted helminth (STH) infections cause a huge burden of disease in the developing world [1], and have been associated with significant educational and nutritional effects [2,3]. School age children suffer from subtle morbidity such as anemia, chronic pain, diarrhea, exercise intolerance, growth stunting, undernutrition and impaired cognitive development, leading to poor school performance [3]. In children and adults, schistosomiasis mansoni can have nonspecific clinical manifestations such as bloody diarrhea and

\footnotetext{
* Correspondence: pmwinzi@kemricdc.org

${ }^{1}$ Neglected Tropical Diseases Branch, Center for Global Health Research, Kenya Medical Research Institute, 1578-40100, Kisumu, Kenya

Full list of author information is available at the end of the article
}

abdominal discomfort, and if untreated can lead to serious liver complications. While this burden is difficult to measure, deaths due to schistosomiasis have been estimated as high as 200,000 per year [3].

In Kenya, over 6 million people are estimated to be infected [1] and many more are at risk. The highest infection rates are found in adolescents aged 10-19 years, but adult workers in rural areas who are employed in activities associated with water contact are also affected [4-6]. Overall, the prevalence of schistosomiasis ranges from $5 \%$ to over $65 \%$ in communities in Kenya and contributes to significant morbidity [5-8]. In the Nyanza region, schistosomiasis is largely associated with Lake Victoria [9]. There are still many areas where the true burden with schistosomiasis is not well known as disease 
mapping has not been adequate. Recent efforts to map schistosomiasis in this setting [10-12] should continue to be encouraged. Prevalence levels among school children along the Lake shores ranged between 29-94\% [10]. In another study, more than $50 \%$ of the children in schools located less than 1 kilometer from the lake were positive for S. mansoni infection. This prevalence decreased with increasing distance from the lake [9].

Often, schistosome infections co-occur with STHs. In Kenya, the prevalence of STHs is prominently attributed to Ascaris lumbricoides, hookworm and Trichuris trichiura $[13,14]$. It is estimated that approximately 10 million Kenyans are infected with STHs and over 12 million people living in rural endemic areas in the country are at risk of infection with these parasites. In Nyanza, up to $50 \%$ of school going children were infected with hookworm, ascarids, or trichurids [14] but there was no effect of lake proximity in the overall distribution of these STHs $[9,14]$.

Despite the importance of schistosomiasis and STHs in Kenya, a National Control Program for the community has not been instituted. However, a national deworming program targeting school aged children was launched by both Ministers of Basic Education and Public Health and Sanitation, and implemented in 45 districts (total districts 254) in year 2009. Currently, school-based deworming is the primary approach being used for mass treatment of schistosomiasis and STHs and has been supported in a few areas in the country, mostly by local and international non-governmental organizations (NGOs). However, this approach is limited by low school enrolment in Kenya despite the introduction of free universal primary education in 2002 as poverty-related indirect costs prevent attendance by many children. Effective control by the school-based strategy may not be possible if other infected members of the community are not treated, such as fishermen, farmers in irrigation schemes, sand harvesters and mothers of child bearing age who can have high levels of infection but are not reached by schoolbased treatment programs. Involvement of communities, both for implementing school-based treatment and for increasing coverage to all those at risk, has not been effectively employed.

To improve access to treatment at affordable and sustainable costs and, where possible, to improve existing programs, community-directed intervention (CDI) has been presented as an alternative strategy for control of schistosomiasis and STHs. The CDI approach has been tried in several settings [15-18] and has worked successfully in many countries for the African Programme for Onchocerciasis Control (APOC) [19-21] as well as for lymphatic filariasis control along the Kenyan coast [22,23].

Effective and safe drugs for treatment of STHs are available in Kenya. However, drugs for treatment of schistosomiasis are not available in the health facilities in the country, and STH treatment is intermittently available in health facilities. Most individuals at high risk of morbidity do not have access to treatment because of the paucity of health infrastructure, lack of awareness about the disease, or cost. Therefore it is pertinent to evaluate if CDI would increase access to treatment among community members as well as increase coverage in school age children. We used the CDI approach for treatment against schistosomiasis and STHs in East Uyoma location of Western Kenya, an area along the shores of Lake Victoria highly endemic for schistosomais and STHs, to test CDI acceptability and effectiveness in reducing disease prevalence and burden.

\section{Methods}

\section{Study area}

This study was conducted in a rural part of Nyanza Province, Western Kenya in Madiany Division, East Uyoma location, within the Health and Demographic Surveillance System (HDSS) platform. This HDSS was established in September 2001 by the Kenya Medical Research Institute and the CDC (KEMRI/CDC) [24]; (Figure 1). East Uyoma location has 25 villages. This study area borders Lake Victoria where earlier surveys had identified schistosomiasis prevalence levels between $30 \%$ to $80 \%$ among highly exposed individuals $[5,6,9]$.

\section{Study design}

\section{Mapping and census of study area}

Village representatives (VR) who had participated in previous studies in the area were asked to help with a map updating exercise. This included confirming compound IDs and mapping any new compounds that had been established since the previous mapping by the KEMRI/ CDC HDSS program. The coastline, which changes over time due to the receding waters of Lake Victoria, was also updated. A database identifying compounds, compound heads, and households in each compound was created and updated maps of the East Uyoma were generated, showing locations of schools and clinics, village boundaries, and other relevant features like rivers or creeks (Figure 1). This database was used to determine geographical treatment coverage and for mapping disease distribution. In total, there are 25 villages in the study area with 2046 compounds and an average 4.05 households per compound. After mapping the village, trained CDDs conducted the village census to determine the number of praziquantel and albendazole tablets required in his/her allocated area. Each CDD was assigned an average of 60 compounds. Compound heads were consented for inclusion of their home compounds in the census in preparation for drug distribution. The census 


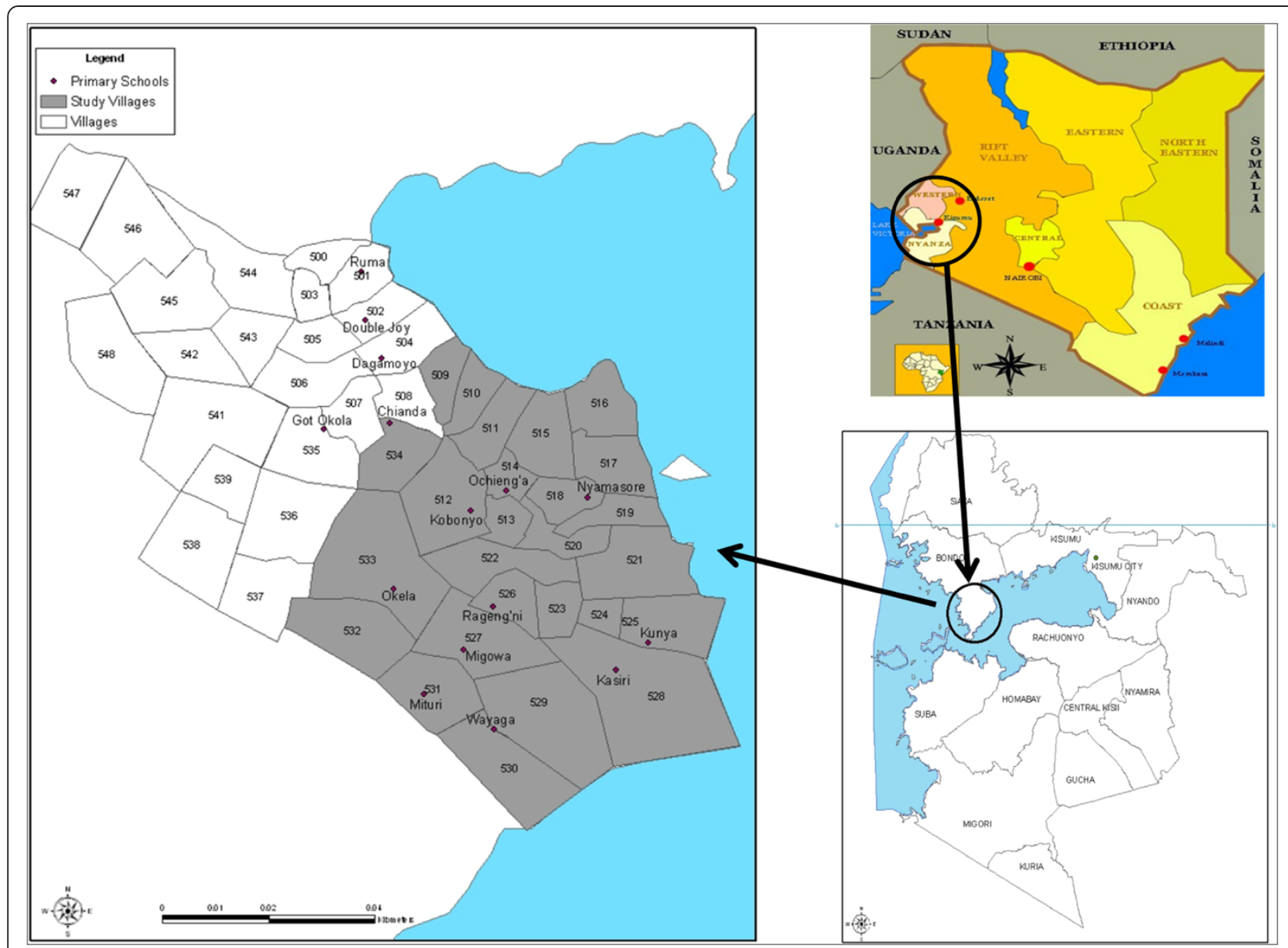

Figure 1 Map of East Uyoma in western Kenya showing study villages along the shores of Lake Victoria.

was conducted by CDDs using pre-designed census booklets

\section{Prevalence survey}

Parasitological surveys were conducted by the research team. Pre-treatment prevalence levels of S. mansoni infections, STH infections and anemia were assessed among standard 4 children aged 9-10 years old in all 10 schools in the study area. Prevalence of infection in school age children was used as a proxy to estimate baseline community prevalence and subsequent treatment coverage [25]. The initial parasitological survey was followed by a post-treatment survey in May 2008, six months after the baseline survey and drug distribution. Through the school leadership, parents of pupils in class 4 were requested to come to the school compound to be informed about the study and to provide consent for their children's participation. Only children of parents who agreed to come to school and gave informed consent and children who gave assent were included in the study. Up to $99 \%$ of parents signed the consent forms. A total of 492 children were included in the study following consent by parents and assent by the children. To assess parasite infections at each survey time, children were asked to provide a single stool sample. Two slides were prepared from each stool sample using the Kato-Katz method and each slide was read by an experienced microscopist. Blood was collected by finger-stick to evaluate hemoglobin $(\mathrm{Hb})$ levels using a Hemacue (Ängelholm, Sweden). Socioeconomic data were also collected from parents of participating children using standardized questionnaires in order to determine if prevalence and CDI uptake levels were related to socioeconomic status.

\section{Community drug distributors (CDD)}

The CDDs were lay persons from the study area who volunteered for this role. CDDs were trained to administer informed consent during census and drug distribution exercises, to distribute the drugs, and to report back to the health facility and researchers. A training curriculum modeled on the Kenya Ministry of Health training kit for teachers was developed and used for the training of CDDs. Each CDD received a manual that included 
basic information about the biology of schistosomes and STHs, treatment guidelines, the goals of CDI and the role of a CDD. CDDs were trained for conducting a census by the research team and local Ministry of Health workers. The CDDs obtained consent from compound heads for the census and of all community members for treatments in the door-to-door drug distribution. The research team administered all other consent, including that for the baseline survey among parents and parasitological survey in children.

\section{Drug distribution}

Praziquantel and albendazole were used for the integrated treatment of schistosomes and STH infections, respectively, among residents aged $\geq 5$ years, using trained community drug distributors (CDD).

Drug distribution treatment was recorded in the same booklet used for the census, allowing for easy follow-up by the CDDs. Doses of drugs were distributed door-todoor to individuals based on their height, excluding children under 5 years old. The drug distribution exercise carried out in December 2007-February 2008 was disrupted by the post-election skirmishes of late December 2007 -January 2008, but some CDDs who had not completed the exercise were able to resume in February 2008.

\section{Praziquantel dosage determination by height}

We modified the tablet pole $[26,27]$ to a version that was light and foldable and therefore very easy to carry by CDDs. The tablet pole had a magnet at the hinge which held the pole firmly straight when unfolded during use. The pole was color coded for easy determination of drug dosage by the CDDs. CDDs recorded the number of drug tablets given to each individual against height by color code on the pole.

\section{Data analysis}

Quantitative data were entered and summarized using MS Access and Excel. Data were analyzed in MS Access, GraphPad Prism and Excel. Pre-treatment and posttreatment prevalence and infection intensity levels were compared using Chi-square and nonparametric t-tests. $P$ values $<0.05$ were considered significant.

\section{Ethical considerations}

This study was reviewed and cleared by the Kenya National Ethics Committee and permission was obtained from District (Bondo) and Divisional (Uyoma) Administration as well as District Education Officers. The project was then introduced to schools through school heads and to the community during community meetings normally called by the location chiefs and village heads. These traditional "barazas" (Chief's meeting) were used for project introduction and information dissemination so as to keep within the normal community structures to ensure sustainability. No parallel community gatherings were introduced. During these meetings, health education was provided to the community. Community members identified one or two CDDs per village, depending on the population.

\section{Results}

\section{Community census}

Results from the census exercise completed by CDDs in October 2008 indicated that there were 5987 adults (persons over 18 years; $57.9 \%$ of the population), 3677 (35.5\%) children over 5 years and 683 (6.6\%) were children under five in East Uyoma, bringing the total population to 10347 and population eligible for treatment to 9664. East Uyoma Location had 25 villages, some of which were sub-divided for our drug distribution convenience, and about 2046 home compounds. According to the 2009 national census data from Kenya Bureau of Statistics, the community had a total population of 15281 which included 7562 (49.5\%) males and 7719 (50.5\%) females, with $9.6 \%(\mathrm{n}=1467)$ of the population being children under 5 and the population eligible for mass treatment being 13814. These data suggest that the CDD census missed about 4934 persons, representing $32.3 \%$ of the population.

\section{Socio-economic survey}

Areas endemic for schistosomiasis and STH infections are usually associated with inadequate sanitation and generally lower living standards. To establish the socioeconomic and water contact levels in relationship to CDI uptake, a socio-economic questionnaire was administered to parents of children in class 4 of all 10 primary schools in the East Uyoma location. Of 404 respondents, the majority of community members (95.3\%) lived on their own land and practiced subsistence farming. Almost everyone (98.3\%) in the community had daily contact with Lake Victoria (34.2\%), a pond/dam (45.4\%) or creek/river (18.6\%), all potential schistosomiasis transmission sites. Only $36.2 \%$ of respondents had access to piped water or a well, whether in their homes $(9.9 \%)$ or in public/community-owned water sources (26.3\%). Sanitation was generally poor. While $60.3 \%$ of people surveyed had pit toilets, $30.2 \%$ did not have access to any sanitation facility and used the open ground for defecation. (Table 1 ). Less than $2 \%$ of the study population owned either a car, refrigerator or had electricity, but a large proportion owned radios (85.1), mobile (cell) phones $(35.2 \%)$ or bicycles $(70.5 \%)$. Only $9.7 \%$ of people who answered the survey had television sets in their homes. The majority of the houses had dirt/earth flooring (82.4\%). Natural/grass roofing was utilized on $42.2 \%$ 
Table 1 Relationship between socio-economic characteristics and prevalence of schistosomiasis and geohelminthic infections in school children

\begin{tabular}{|c|c|c|c|c|}
\hline \multicolumn{3}{|c|}{ Socio-economic data $n=404$} & \multicolumn{2}{|c|}{ Frequency and distribution of parasites $\%(n)$} \\
\hline & $\mathrm{N}$ & $\%$ & S. mansoni\% (n) & Any STH (HW, TT, Asc)\% (n) \\
\hline \multicolumn{5}{|c|}{ Water Contact: Lake Victoria } \\
\hline Everyday & 138 & 34.2 & $18.25(23)$ & $14.96(19)$ \\
\hline Sometimes & 82 & 20.3 & $25.00(17)$ & $20.59(14)$ \\
\hline Rarely & 64 & 15.9 & $12.96(7)$ & $25.93(14)$ \\
\hline Never & 119 & 29.5 & $12.62(13)$ & $21.36(22)$ \\
\hline \multicolumn{5}{|l|}{ Pond or Dam } \\
\hline Everyday & 183 & 45.4 & $10.49(17)$ & $17.79(29)$ \\
\hline Sometimes & 59 & 14.6 & $20.75(11)$ & $20.75(11)$ \\
\hline Rarely & 35 & 8.7 & $17.24(5)$ & $34.48(10)$ \\
\hline Never & 120 & 29.8 & $24.00(24)$ & $17.00(17)$ \\
\hline \multicolumn{5}{|l|}{ Creek or River } \\
\hline Everyday & 75 & 18.6 & $17.39(12)$ & $15.94(11)$ \\
\hline Sometimes & 55 & 13.6 & $22.73(10)$ & $25.00(11)$ \\
\hline Rarely & 43 & 10.7 & $14.63(6)$ & $21.95(9)$ \\
\hline Never & 220 & 54.3 & $15.14(28)$ & 19.46 (36) \\
\hline \multicolumn{5}{|l|}{ Drinking water } \\
\hline Own pipe & 23 & 5.7 & $8.70(2)$ & 17.39 (4) \\
\hline Public pipe & 106 & 26.3 & $11.32(12)$ & $20.75(22)$ \\
\hline Own Well & 17 & 4.2 & $23.53(4)$ & $5.88(1)$ \\
\hline Public well & 52 & 12.9 & 5.77 (3) & $15.38(8)$ \\
\hline Rain water & 65 & 16.1 & $10.77(7)$ & $6.15(4)$ \\
\hline River/canal & 85 & 21.1 & $12.94(11)$ & $12.94(11)$ \\
\hline Other & 121 & 30.0 & $18.18(22)$ & $11.57(14)$ \\
\hline \multicolumn{5}{|l|}{ Type of toilet } \\
\hline Own flush & 2 & 0.5 & $50.00(1)$ & 0 \\
\hline Shared flush & 1 & 0.3 & 0 & 0 \\
\hline Pit latrine & 244 & 60.3 & $12.30(30)$ & $17.62(43)$ \\
\hline VIP & 1 & 0.3 & & \\
\hline Bush/field & 146 & 36.2 & $18.49(27)$ & 19.05 (24) \\
\hline other & 5 & 1.2 & 0 & 0 \\
\hline \multicolumn{5}{|l|}{ Housing } \\
\hline Electricity & 7 & 1.7 & 0 & 0 \\
\hline Fridge & 1 & 0.3 & 0 & 0 \\
\hline Car & 1 & 0.3 & 0 & 0 \\
\hline Telephone & 142 & 35.2 & $17.65(21)$ & $21.74(25)$ \\
\hline Radio & 344 & 85.1 & $17.06(50)$ & $19.73(58)$ \\
\hline Bicycle & 285 & 70.5 & $18.57(44)$ & $18.91(45)$ \\
\hline TV & 39 & 9.7 & $11.54(3)$ & $23.08(6)$ \\
\hline Motor bike & 3 & 0.7 & 0 & $19.54(68)$ \\
\hline Domestic worker & 27 & 6.7 & $9.09(2)$ & $22.73(22)$ \\
\hline SES quintile (1-4) & 142 & 42.13 & $16.20(23)$ & $22.54(32)$ \\
\hline SES quintile (5) & 195 & 57.86 & $15.38(30)$ & $18.46(36)$ \\
\hline
\end{tabular}


of the houses and $56.1 \%$ had corrugated iron roofing. Previous interventions for parasitic diseases in the area had resulted in limited success with $41.7 \%$ of survey participants having bed nets in their homes, $68.4 \%$ of those nets had been treated regularly. No infections were found among the few children from families that had electricity or owned a car or a refrigerator. However, we did not find any relationship between overall socioeconomic status $\mathrm{Z}$ scores and infection levels in individual children, prevalence level by village, or CDI coverage. This is perhaps because all the villages were close to the lake (all within 5KM of the shore) and exposure levels among children were not significantly different.

\section{Disease distribution}

Pre-treatment prevalence levels of $S$. mansoni in East Uyoma schools ranged from $5 \%$ to $43.2 \%$ with an average prevalence of $17.8 \%$. Mean intensity ( \pm SD) of eggs per gram (EPG) was $166.8 \pm 295.1$ (range 12-1560; CI: 99.8 222.0). At the six month follow-up, 576 children were surveyed. S. mansoni infections were detected in 38 out of 84 new children who had recently joined the schools and had not participated in the baseline survey. This migration was mostly caused by the post-election violence and led to higher post-treatment prevalence levels in two schools. When the comparison was limited to children surveyed at baseline, there was a $33.2 \%$ reduction in mean school prevalence of $S$. mansoni $(\mathrm{P}=0.04)$, a $69.4 \%$ reduction in hookworm prevalence $(\mathrm{P}=0.003)$, a $1.8 \%$ decrease in prevalence of $A$. lumbricoides (NS) and a $42.6 \%$ reduction in $T$. trichiura prevalence $(\mathrm{P}=0.027)$ (Figure 2A). Mean intensity ( \pm SD) of S. mansoni infection EPG after mass treatment was reduced to $60.3 \pm 70.9$ (range 12-322; CI: 7.6-46.9). Mean Hb levels were $12.5 \pm 1.9 \mathrm{~g} / \mathrm{dl}$ and ranged from $5.1 \mathrm{~g} / \mathrm{dl}$ to $18.5 \mathrm{~g} /$ dl. Hemoglobin levels increased by $0.4 \mathrm{~g} / \mathrm{dl}$ from baseline, but the difference was not statistically significant (Figure 2B).

\section{Household survey}

The household survey was used to assess treatment coverage and occurrence of side effects. Sixteen villages were randomly selected for a household survey and assigned to 10 interviewers who walked door-to-door administering post-treatment questionnaires to households. The interviewers were CDDs from different villages from those they were assigned to survey. Each interviewer was asked to randomly interview $50 \mathrm{com}$ pounds in each selected village, but an average of only 35.7 (range 13-50) compounds were visited per village, totalling 785 compounds. At the end of 2 weeks, records were retrieved from the interviewers and analyzed. Reasons for the low coverage of compounds by some of the CDDs included interviewer's inability to access some homes and the slow pace and poor performance of some of the community interviewers. According to the CDD house-hold survey records, the average age of the head of compound was 53.8 years (31.1 -59.6 years). The 785 compounds included in the household survey had an average $( \pm$ SD) 4.0 households and $12.6 \pm 2.6$ persons per compound. An average of $7.9 \pm 2.0$ persons per compound reported receiving treatment, $5.9 \pm 3.1$ persons reported not receiving treatment and an average of $1.2 \pm 0.4$ persons per compound were reported absent.

\section{Treatment coverage}

Treatment coverage for praziquantel and albendazole was assessed from CDD registers, but since coverage values obtained from the community registers of the CDDs may be unreliable[28], coverage was also assessed through a household survey using a questionnaire for parents/household heads. The questionnaires were administered in randomly selected households in the communities and administered to all members of the household present at the time of the survey. A total of 8103 persons were treated according to CDD registers. Treatment coverage was calculated as the total number of persons treated divided by total eligible population (persons over 5 years of age) and expressed as a percentage. The percentage of persons treated according to CDD records ranged from $54.2 \%-96.6 \%$ in individual villages $(77.5 \% \pm 16.8 ; \mathrm{n}=8103)$. In six villages (Matera, Ukunja, Migowa, Okela, Osewere, and Kakremba), incomplete CDD records were returned after one CDD found a different job before completing the treatment exercise (Matera village); 4 CDDs were offered paid jobs as election clerks in the area before they could complete the treatment exercise and one CDD migrated away from the area (Kakremba village). Other volunteers completed the exercise in those areas after our surveys. Coverage in other areas where treatment was completed ranged from $52.1 \%$ - $90.3 \%$. There was a significant difference between coverage by CDD records, $77.5 \pm 16.8 \%$, and coverage per total population determined by the household survey, $58.2 \%(\mathrm{P}<0.01$; ANOVA $)$ ), which was also comparable to the coverage when official national census population data were used as the denominator $(53.0 \%$ of the total population and $58.6 \%$ of the eligible population). Because the area was mapped before the treatment exercise and all the home compounds in the location were recorded, it was possible to estimate coverage from the CDD records by analyzing the number of compounds visited. This revealed that even though a CDD record may show very high coverage, such coverage was only based on those compounds that had been visited and recorded by the CDD and not necessarily all compounds. According to this analysis, Nyamboi and Kayundi had compound coverage of $23.4 \%$ and $33.1 \%$ 
A

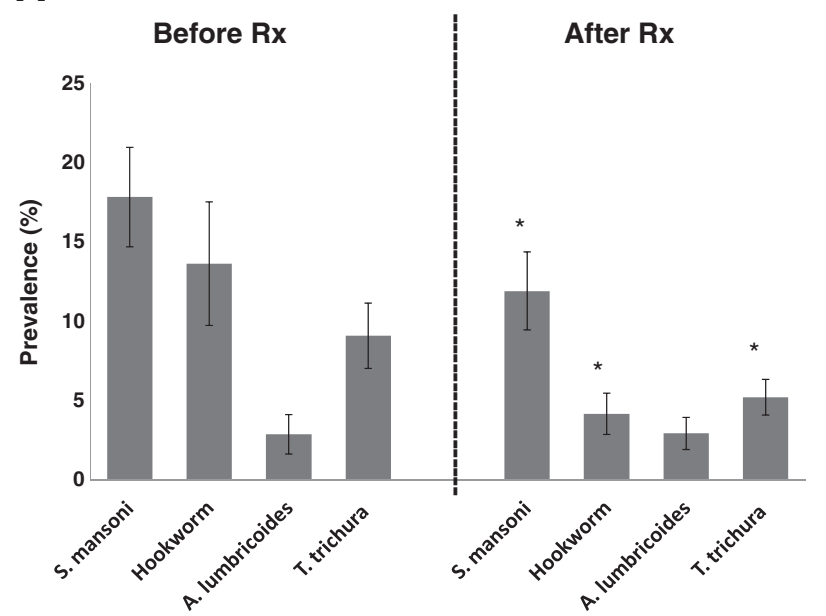

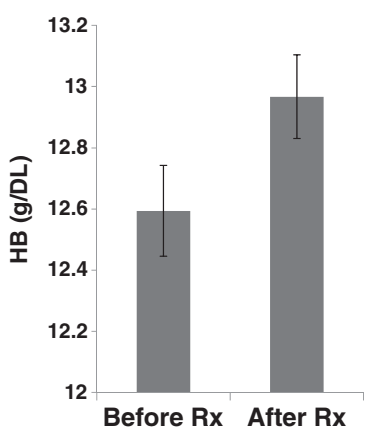

Figure 2 Comparison of parasite prevalence levels following one round of mass drug distribution. A. Prevalence levels for $S$. mansoni, hookworm, A.lumbricoides and Trichuris trichura compared before and after treatment with praziquantel and albendazole. Error bars represent standard deviation (SD) of means. * represents significant change in prevalence following treatment $\mathbf{B}$. Haemoglobin levels compared before and after treatment

but treatment coverage of $77.5 \%$ and $75.9 \%$ respectively (Table 2).

\section{Side effects}

Praziquantel is generally safe and usually only causes minor side effects that usually resolve with minimal management. Side effects following treatment were recorded during the household survey. Reported side effects were minor with $12.7 \%(n=279), 34.2 \%(n=752)$, $4.7 \%(n=103)$ and $0.3 \%(n=21)$ of those treated reporting diarrhea, fatigue, abdominal pain and vomiting, respectively. Fatigue was the most common reported side effect. Overall, $48.7 \%$ of those treated reported one or more of these minor side effects.

\section{Drug costs}

The financial cost of praziquantel for treated persons was $\$ 9,865.85$, for an average cost per treatment of $\$ 0.98$, while the cost for albendazole treatment was $\$ 0.23$ per dose. These drugs were purchased by the project because at the time of the study, free or subsidized drugs were not available from the public health sector. Economic costs associated with the drug distribution were not evaluated as part of this study.

\section{Discussion}

With renewed interest in the control of schistosomiasis and other neglected tropical diseases (NTDs), both by global sponsors and governments in endemic regions, evidence based data on cost effective strategies for mass drug administration are needed to inform control and elimination program managers. Adhering to strategic guidelines issued by the World Health Organization, the main approach has been to use school-based mass treatment for controlling schistosomiasis in highly endemic areas. However, it is recognized that this approach leaves out other members in the community who are also infected and who may be contributing to continued transmission. In recent years, community based treatment has been tested as an alternate approach but community-level programs may be limited by inadequate health care infrastructure at the primary level in many areas of Africa [29,30]. In Kenya, although the government recognizes the importance of local interventions and having policies for preventive approaches for health care, allocation of health resources has been skewed in favor of tertiary and secondary facilities that offer curative services. This approach ignores rural health facilities that are the first point of patient contact and provide the bulk of the healthcare services [31].

As an example of a primary health care level program, CDI has been evaluated and found to be highly successful in reaching persons at risk of disease within the community [32]. CDI emphasizes the significant role of communities as lead partners and is the fundamental factor that has been responsible for the success of APOC. Systematic reviews have shown that the use of community or lay health workers who are trained in the context of the intervention but who have no formal professional or tertiary education in preventative health care, showed promising benefits. Compared with usual care, lay health workers increased the uptake of childhood immunization, promoted breastfeeding, reduced childhood mortality and morbidity from common childhood illnesses, and 
Table 2 Drug distribution coverage by homestead compounds visited, CDD records, and household survey (HHS)

\begin{tabular}{|c|c|c|c|c|c|}
\hline Village & $\begin{array}{l}\text { Number of } \\
\text { Compounds }\end{array}$ & $\begin{array}{c}\text { Percent (\%) } \\
\text { compounds visited }\end{array}$ & $\mathrm{n}$ (persons) & $\begin{array}{l}{ }^{a} \text { Percent } \% \text { coverage } \\
\text { by CDD Record }\end{array}$ & $\begin{array}{c}{ }^{a} \text { Percent } \% \text { coverage } \\
\text { by HHS }\end{array}$ \\
\hline Agege & 35 & 67.7 & 710 & 71.1 & 75.9 \\
\hline Andom A & 26 & 87.7 & 372 & 61.3 & 52.1 \\
\hline Andom B & 22 & 90.5 & 227 & 54.2 & 57.4 \\
\hline Chianda & 26 & 52.3 & 231 & 80.1 & 74.8 \\
\hline Got-Kachola & 21 & 85.6 & 616 & 89.6 & 90.3 \\
\hline${ }^{\beta}$ Kakremba & 50 & 74.6 & 438 & 95.7 & 20.1 \\
\hline Kasiri & 16 & 71.9 & 679 & 80.3 & ND \\
\hline Kayundi & 49 & 38.1 & 162 & 75.9 & ND \\
\hline Kunya & 28 & 67.6 & 558 & 77.4 & 61.4 \\
\hline Magombe & 25 & 77.5 & 612 & 91.1 & 89.0 \\
\hline Maranba & 51 & 61.6 & 397 & 54.9 & 62.2 \\
\hline${ }^{\beta}$ Matera & 50 & 67.2 & 449 & 26.7 & ND \\
\hline${ }^{\beta}$ Migowa & 30 & 59.7 & 451 & 86.9 & 37.3 \\
\hline Mituri & 21 & 80.4 & 503 & 73.6 & 71.3 \\
\hline Mochi & 98 & 77.8 & 394 & 98.5 & ND \\
\hline Nyagunda & 26 & 64.2 & 552 & 73.2 & 62.4 \\
\hline Nyamasore A & 21 & 50.7 & 196 & 61.2 & ND \\
\hline Nyamasore B & 30 & 64.6 & 173 & 77.5 & ND \\
\hline Nyamboi & 48 & 23.4 & 71 & 77.5 & ND \\
\hline Ochienga & 50 & 90.0 & 446 & 68.6 & ND \\
\hline Odede & 25 & 85.2 & 388 & 93.3 & 55.9 \\
\hline Okela & 25 & 63.3 & 553 & 81.2 & 61.4 \\
\hline${ }^{\beta}$ Ukunja & 50 & 77.5 & 320 & 95.6 & 35.7 \\
\hline${ }^{\beta}$ Osewre & 35 & 91.9 & 235 & 96.6 & 49.0 \\
\hline Wayaga & 13 & 81.4 & 614 & 94.9 & ND \\
\hline Total or Average & 871 & 67.53 & 10347 & 77.47 & 58.1641 \\
\hline
\end{tabular}

${ }^{a} P=0.0047$ (Paired t) for comparison between CDD record for coverage and independent household survey.

${ }^{\beta}$ CDDs quit exercise before completing drug distribution.

improved outcomes of tuberculosis treatment [33]. In a study by Ndyomugyenyi and Kabatereine [18], integrated CDI achieved higher treatment coverage (85\%) for praziquantel and mebendazole compared to a school-based treatment approach (79\%) for children aged 5-14 years. Moreover, CDI is able to reach other at risk groups in the community outside of the school system. However, more controlled studies comparing the CDI and school-based mass-drug administrations in endemic areas are needed.

The aim of this project was to pilot and evaluate the CDI approach for treatment against schistosomiasis and STHs in a rural setting in Nyanza Province, western Kenya, which is outside the APOC zone and therefore untested for CDI. In the current study, the CDDs visited $67.5 \%$ of the mapped compounds and achieved an overall coverage of $58.2 \%$ as determined by household survey. The effectiveness of CDI coverage was influenced by several factors. Coverage depended on accurate mapping of the targeted treatment area by compound because CDD records were based on only the compounds that the CDD had visited; as a result, they overestimated coverage (Table 2). Further, sociopolitical factors may have influenced the study results and the success of CDI. This CDI coincided with the 5-yearly election period in Kenya, which presented a difficult challenge to many CDDs. The political tension in the community affected the general acceptability of CDDs in homes where they were perceived to be of different political persuasions. Moreover, the community focus on election campaigns led to increased absenteeism from homes. Even with these difficulties, many villages were able to achieve appreciable coverage levels.

In this study, the praziquantel cost was $\$ 0.98$ per delivered treatment and the albendazole cost was $\$ 0.23$ per delivered treatment. These drugs were not provided by the donor-subsidized public health sector where it would 
have been expected that drug costs would be much cheaper or even free. Reducing the cost of praziquantel should be an encouragement to both private and public sectors to implement mass drug distribution programs. These results confirm that praziquantel is well tolerated, causing only minor side effects. However, community wide rumors on drug reactions can adversely affect well organized mass treatments. To help alleviate fears of drug reactions in communities and promote MDA compliance, large-scale control programmes should include pharmacovigilance studies as part of ongoing monitoring and evaluation strategies. Detailed pharmacovigilance data that are disseminated back to the community will provide accurate information to communities about the exact nature, extent and cause of side effects as well as help to discriminate true side effects from other underlying conditions and exaggerated rumors about drug reactions.

\section{Conclusion}

The impact of this one round of drug distribution in a troubled area confirms the feasibility of using CDI for the control of helminth infections in endemic communities. A recently concluded multi-country study on CDI in areas already participating in onchocerciasis control [16] has demonstrated that the CDI process/approach can be effective and feasible for integrated delivery of different health interventions in rural Africa $[16,19]$. Future testing of CDI should be aimed at testing how CDI may be used widely for multiple interventions to strengthen primary health care at the national level and could integrate with other established control programs such as HIV, TB, malaria and maternal and child health $(\mathrm{MCH})$ programs. As the Kenya Ministry of Health continues to roll out the Community Health Strategy, the future role of CDDs will be taken up by community health workers and be more integrated with other community level health activities. It will be helpful to evaluate these developments as they occur. Currently, we are conducting studies to test how elements of the CDI may be used to strengthen the Kenya Ministry of Health's community strategy and thereby improve primary health care in rural Kenya. Similar studies in the same setting are comparing community wide treatment to school based treatment in a randomized controlled trial. We are also preparing reports on qualitative findings describing community acceptability of the CDI approach in this setting. This pilot study paves the way for larger scale trials to compare community wide treatments to school-based strategies in the country.

\section{Competing interests}

The authors have no interests to declare.

\section{Authors' contributions}

PNMM provided overall study supervision, data analysis and prepared the manuscript. SPM carried out sample size calculations and data analysis. COO and EMM were involved with community mobilization and data collection. PNMM, MM, JGA, KFL, EMM, WES, DMSK designed the study. All authors reviewed analyzed data and approved the manuscript.

\section{Acknowledgements}

This work is published with the permission of the Director, Kenya Medical Research Institute. The findings and conclusions in this report are those of the authors and do not necessarily represent the views of the CDC. The authors would like to thank Maurice Ombok, Nicholas Mwaura and Esther Tolo for help with data management. COO and the project activities were supported by WHO/TDR Business Line 11 grant \# A 60476 to PNMM. All other authors were supported by their respective institutions.

\section{Author details}

${ }^{1}$ Neglected Tropical Diseases Branch, Center for Global Health Research, Kenya Medical Research Institute, 1578-40100, Kisumu, Kenya. ${ }^{2}$ Ministry of Public Health and Sanitation, Division of Vector Borne and Neglected Tropical Diseases, Nairobi, Kenya. ${ }^{3}$ Centers for Disease Control and Prevention, Division of Parasitic Diseases and Malaria, Atlanta, GA, USA. ${ }^{4}$ KEMRI/CDC Research and Public Health Collaboration, Center for Global Health Research, Kenya Medical Research Institute (KEMRI/CDC), 1578-40100, Kisumu, Kenya.

Received: 24 January 2012 Accepted: 17 July 2012

Published: 31 August 2012

\section{References}

1. Chitsulo L, Engels D, Montresor A, Savioli L: The global status of schistosomiasis and its control. Acta Trop 2000, 77(1):41-51.

2. Stephenson $\mathrm{L}$ : The impact of schistosomiasis on human nutrition. Parasitology 1993, 107(Suppl):S107-123.

3. King CH, Dickman K, Tisch DJ: Reassessment of the cost of chronic helmintic infection: a meta-analysis of disability-related outcomes in endemic schistosomiasis. Lancet 2005, 365(9470):1561-1569.

4. Grzych JM, Dissous C, Capron M, Torres S, Lambert PH, Capron A: Schistosoma mansoni shares a protective carbohydrate epitope with keyhole limpet hemocyanin. J Exp Med 1987, 165(3):865-878.

5. Karanja DM, Colley DG, Nahlen BL, Ouma JH, Secor WE: Studies on schistosomiasis in western Kenya: I Evidence for immune-facilitated excretion of schistosome eggs from patients with Schistosoma mansoni and human immunodeficiency virus coinfections. Am J Trop Med Hyg 1997, 56(5):515-521.

6. Karanja DM, Boyer AE, Strand M, Colley DG, Nahlen BL, Ouma JH, Secor WE: Studies on schistosomiasis in western Kenya: II. Efficacy of praziquantel for treatment of schistosomiasis in persons coinfected with human immunodeficiency virus-1. Am J Trop Med Hyg 1998, 59(2):307-311.

7. Ouma $\mathrm{JH}$, Vennervald BJ, Butterworth AE: Morbidity in schistosomiasis: an update. Trends Parasitol 2001, 17(3):117-118.

8. Mwinzi PN, Karanja DM, Kareko I, Magak PW, Orago AS, Colley DG, Secor WE: Short report: Evaluation of hepatic fibrosis in persons co-infected with Schistosoma mansoni and human immunodeficiency virus 1. Am J Trop Med Hyg 2004, 71(6):783-786.

9. Handzel T, Karanja DM, Addiss DG, Hightower AW, Rosen DH, Colley DG, Andove J, Slutsker L, Secor WE: Geographic distribution of schistosomiasis and soil-transmitted helminths in Western Kenya: implications for anthelminthic mass treatment. Am J Trop Med Hyg 2003, 69(3):318-323.

10. Standley C, Lwambo N, Lange C, Kariuki H, Adriko M, Stothard J: Performance of circulating cathodic antigen (CCA) urine-dipsticks for rapid detection of intestinal schistosomiasis in schoolchildren from shoreline communities of Lake Victoria. Parasit Vectors, 3(1):7. doi:10.1186/1756-3305-3-7.

11. Kabatereine NB, Standley CJ, Sousa-Figueiredo JC, Fleming FM, Stothard JR Talisuna A, Alan Fenwick A: Integrated prevalence mapping of schistosomiasis, soil-transmitted helminthiasis and malaria in lakeside and island communities in Lake Victoria, Uganda. Parasites \& Vectors 2011 4(232). doi:10.1186/1756-3305-4-232.

12. Standley CJ, Adriko M, Besigye F, Kabatereine NB, RJS: Confirmed local endemicity and putative high transmission of Schistosoma mansoni in 
the Sesse Islands, Lake Victoria, Uganda. Parasites \& Vectors 2011, 4(29). doi:10.1186/1756-3305-4-29.

13. Brooker S, Miguel EA, Moulin S, Luoba Al, Bundy DA, Kremer M: Epidemiology of single and multiple species of helminth infections among school children in Busia District, Kenya. East Afr Med J 2000, 77(3):157-161.

14. Clements AC, Deville MA, Ndayishimiye O, Brooker S, Fenwick A: Spatial co-distribution of neglected tropical diseases in the east African great lakes region: revisiting the justification for integrated control. Trop Med Int Health 2010, 15(2):198-207.

15. Wanji S, Tendogfor N, Nji T, Esum M, Che JN, Nkwescheu A, Alassa F, Kamnang G, Enyong PA, Taylor MJ, Hoerauf A, Taylor DW: Communitydirected delivery of doxycycline for the treatment of onchocerciasis in areas of co-endemicity with loiasis in Cameroon. Parasites and Vectors 2009, 2(1):39.

16. CDI Study Group: Community-directed interventions for priority health problems in Africa: results of a multicountry study. Bulletin of the World Health Organization 2010, 88(7):509-518.

17. Mutalemwa P, Kisinza WN, Kisoka WJ, Kilima S, Njau J, Tenu F, Nkya T, Magesa SM: Community directed approach beyond ivermectin in Tanzania: a promising mechanism for the delivery of complex health interventions. Tanzanian Journal of Health Research 2009, 11:116-125.

18. Ndyomugyenyi R, Kabatereine N: Integrated community-directed treatment for the control of onchocerciasis, schistosomiasis and intestinal helminths infections in Uganda: advantages and disadvantages. Trop Med Int Health 2003, 8(11):997-1004.

19. Homeida M, Braide E, Elhassan E, Amazigo UV, Liese B, Benton B, Noma M, Etya'ale D, Dadzie KY, Kale OO, et al: APOC's strategy of communitydirected treatment with ivermectin (CDTI) and its potential for providing additional health services to the poorest populations. African Programme for Onchocerciasis Control. Ann Trop Med Parasitol 2002, 96(Suppl 1):S93-104.

20. Sama MTH, Ngang P, Liese BH, Amazigo U, Seketeli A: A multi-centre study of community-directed ivermectin distributors' (CDDs') involvement in other healthcare and development programme activities in Cameroon, Togo, Sudan, Nigeria and Uganda. Tropical Doctor 2003, 33(4):237-241.

21. Seketeli A, Adeoye G, Eyamba A, Nnoruka E, Drameh P, Amazigo UV, Noma M, Agboton F, Aholou Y, Kale OO, et al: The achievements and challenges of the African Programme for Onchocerciasis Control (APOC). Ann Trop Med Parasitol 2002, 96(Suppl 1):S15-S28.

22. Wamae CN, Njenga SM, Ngugi BM, Mbui J, Njaanake HK: Evaluation of effectiveness of diethylcarbamazine/albendazole combination in reduction of Wuchereria bancrofti infection using multiple infection parameters. Acta Tropica 2010, 120(1):1-186.

23. Njenga SM, Wamae CN, Njomo DW, Mwandawiro CS, Molyneux DH: Impact of tworounds of mass treatment with diethylcarbamazine plus albendazole on Wuchereriabancrofti infection and the sensitivity of immunochromatographic test in Malindi, Kenya. Transactoins Royal Society Tropical Medicine and Hygiene 2008, 102(10):1017-1024.

24. Adazu K, Lindblade KA, Rosen DH, Odhiambo F, Ofware $P$, Kwach J, Van Eijk AM, Decock KM, Amornkul P, Karanja D, et al: Health and demographic surveillance in rural western Kenya: a platform for evaluating interventions to reduce morbidity and mortality from infectious diseases. Am J Trop Med Hyg 2005, 73(6):1151-1158.

25. Amazigo UV, Brieger WR, Katabarwa M, Akogun O, Ntep M, Boatin B, N'Doyo J, Noma M, Seketeli A: The challenges of community-directed treatment with ivermectin (CDTI) within the African Programme for Onchocerciasis Control (APOC). Ann Trop Med Parasitol 2002,

96(Suppl 1):S41-S58.

26. Hall A, Nokes C, Wen ST, Adjei S, Kihamia C, Mwanri L, Bobrow E, de Graft-Johnson J, Bundy D: Alternatives to bodyweight for estimating the dose of praziquantel needed to treat schistosomiasis. Trans $R$ Soc Trop Med Hyg 1999, 93(6):653-658.

27. Montresor A, Engels D, Chitsulo L, Bundy DA, Brooker S, Savioli L: Development and validation of a 'tablet pole' for the administration of praziquantel in sub-Saharan Africa. Trans R Soc Trop Med Hyg 2001, 95(5):542-544.

28. Ndyomugyenyi R, Remme J: Using ivermectin-treatment coverage among schoolchildren monitored by schoolteachers as a proxy of population coverage in areas of Uganda where onchocerciasis is endemic. Ann Trop Med Parasitol 2002, 96(1):53-60
29. Kager PA: Malaria control: constraints and opportunities. Trop Med Int Health 2002, 7(12):1042-1046.

30. Moerman F, Lengeler C, Chimumbwa J, Talisuna A, Erhart A, Coosemans M, D'Alessandro U: The contribution of health-care services to a sound and sustainable malaria-control policy. Lancet Infect Dis 2003, 3(2):99-102.

31. Glenngard AH, Maina TM: Reversing the trend of weak policy implementation in the Kenyan health sector?-a study of budget allocation and spending of health resources versus set priorities. Health Res Policy Syst 2007, 5:3

32. APOC report. 2006. http://www.who.int/tdr/publications/publications/pdf/ cdti.pdf (Accessed January 2010).

33. Lewin S, Lavis JN, Oxman AD, Bastías G, Chopra M, Ciapponi A, Flottorp S, Martí SG, Pantoja T, Rada G, et al: Supporting the delivery of cost-effective interventions in primary health-care systems in low-income and middle-income countries: an overview of systematic reviews. Lancet 2008, 372(9642):928-939.

doi:10.1186/1756-3305-5-182

Cite this article as: Mwinzi et al:: Integrated community-directed intervention for schistosomiasis and soil transmitted helminths in western Kenya - a pilot study. Parasites \& Vectors 2012 5:182.

\section{Submit your next manuscript to BioMed Central and take full advantage of:}

- Convenient online submission

- Thorough peer review

- No space constraints or color figure charges

- Immediate publication on acceptance

- Inclusion in PubMed, CAS, Scopus and Google Scholar

- Research which is freely available for redistribution

Submit your manuscript at www.biomedcentral.com/submit
C) Biomed Central 